\title{
UJI MACAM PUPUK ORGANIK TERHADAP PERTUMBUHAN DAN HASIL 2 VARIETAS TANAMAN STEVIA (Stevia rebaudiana Bertonii M)
}

\author{
Futta Ifnu Guzali*, Dewi Ratna Nurhayati, Siswadi \\ Fakultas Pertanian, Universitas Slamet Riyadi, Surakarta \\ "E-mail: futtaifnuguzali5@gmail.com
}

\begin{abstract}
Info Artikel
Keywords: Organic

Fertilizers, Stevia Varieties

Kata kunci:

Pupuk organik, Varietas Tanaman Stevia

Abstract

Research on Organic Fertilizer Tests on Growth and Yield of 2 Stevia Plant Varieties (Stevia rebaudiana Bertonii M) "has been conducted from September 5, 2019 to November 22, 2019, located in Tlogodringo Hamlet, Gondosuli Village, Tawangmangu District, Karanganyar District. At an altitude of 18000 masl. This study was to examine the types of organic fertilizer on the growth and yield of 2 Stevia plant varieties. This study uses a Complete Randomized Block Design (RCBD) consisting of 2 factors: The first factor is the type of organic fertilizer $(P)$, consisting of 5 types, namely: P0: No fertilizer, P1: Cow manure fertilizer, P2: Goat manure fertilizer, P3 Chicken manure fertilizer, P4: Petroganik Fertilizer, The second factor is the type of variety $(V)$, which consists of 2 levels, namely: V1 (Jumbo Green), V2 (Super Yellow). Based on the results of the study showed that the treatment of organic fertilizer had a significant effect on the growth and yield of Stevia plants both on Green Jumbo varieties (V1) and on Super Yellow varieties (V2), while the treatment without fertilizer had no significant effect on Green Jumbo (V1) and Super Yellow (V1) varieties V2) Petroganic fertilizer treatment does not significantly affect the growth and yield of stevia plants when compared to the treatment without fertilizer. The use of chicken manure fertilizer at a dose of $2 \mathrm{~kg} /$ per plot showed vegetative growth of stevia plants higher than all treatments tested, both in Green Jumbo varieties (V1) and Super Yellow Varieties (V2).

\section{Abstrak}

Penelitian Uji Macam Pupuk Organik Terhadap Pertumbuhan Dan Hasil 2 Varietas Tanaman Stevia (Stevia rebaudiana Bertonii M) telah dilaksanakan mulai tanggal 05 September 2019 sampai tanggal 22 November 2019, bertempat di Dusun Tlogodringo, Desa Gondosuli, Kecamatan Tawangmangu, Kabupaten Karanganyar. Pada ketinggian $18000 \mathrm{mdpl}$ penelitian ini untuk menguji macam pupuk organik terhadap pertumbuhan dan hasil 2 varietas tanaman Stevia. Penelitian ini menggunakan Rancangan Acak Kelompok Lengkap (RAKL) terdiri dari 2 faktor, faktor pertama adalah macam pupuk organik $(\mathrm{P})$, terdiri dari 5 macam, yaitu $\mathrm{P}_{0}$ : Tanpa pupuk, $\mathrm{P}_{1}$ : Pupuk kotoran sapi; $\mathrm{P}_{2}$ : Pupuk kotoran kambing; $\mathrm{P}_{3}$ Pupuk kotoran ayam; $\mathrm{P}_{4}$ : Pupuk Petroganik, Faktor kedua adalah macam varietas $(\mathrm{V})$, yang terdiri dari 2 taraf, yaitu $\mathrm{V}_{1}$ (Jumbo Hijau), $\mathrm{V}_{2}$ (Super Kuning). Berdasarkan hasil penelitian menunjukkan Perlakuan pupuk organik berpegaruh nyata terhadap pertumbuhan dan hasil tanaman Stevia baik pada vaeietas Jumbo Hijau (V1) maupun pada varietas Super Kuning (V2), sedangkan perlakuan tanpa pupuk tidak berpengaruh nyata pada varieats Jumbo Hijau (V1) maupun Super Kuning (V2) Perlakuan pupuk Petroganik tidak berpengaruh nyata terhadap
\end{abstract}


pertumbuhan dan hasil tanaman stevia jika dibandingkan dengan perlakuan tanpa pupuk. Pengunaan pupuk kotoran ayam dengan dosis $2 \mathrm{~kg} /$ per petak menunjukkan pertumbuhan vegetatif tanaman stevia lebih tinggi dari semua perlakuan yang di uji, baik pada varietas Jumbo Hijau (V1) Dan Varietas Super Kuning (V2)

\section{PENDAHULUAN}

Seiring meningkatnya industri pangan dan jumlah penduduk menyebabkan kebutuhan gula terus mengalami peningkatan setiap tahunnya. Pada tahun 2017 pemerintah indonesia melakukan impor gula sebesar 1,3 juta ton untuk mengurangi ketergantungan impor gula tersebut perlu mengembangkan komoditi selain tebu yang dapat digunakan sebagai bahan pemanis alami (Kementrian Pertanian 2012).

Tanaman stevia merupakan alternatif pemanis alami yang mempunyai potensi tersebut (Syukur, 1996). Menurut Seema, (2010) Kandungan kalori dari tanaman stevia dapat digunakan sebagai anti bakteri, anti jamur, diuretik, hipoglikemia bagi para penderita diabetes. Tanaman stevia merupakan tanaman perdu tahunan, yang memiliki bentuk batang bulat, beruas, berbulu, bercabang banyak, dan dapat tumbuh mencapai 40-60 cm dengan bentuk daun lonjong memanjang dengan panjang 2-4 cm, lebar 1-5 cm, dengan daun yang bergerigi halus dan berhadapan, tanaman ini dapat tumbuh dan berproduksi dengan baik di dataran tinggi dengan ketinggian tempat 700-1200 mdpl dengan suhu udara $14^{\circ} \mathrm{C}-27^{\circ} \mathrm{C}$ dan mempunyai curah hujan antara $1600-1850 \mathrm{~mm} /$ tahun, tanaman stevia termasuk tanaman berhari pendek, yang cepat berbunga bila panjang hari kurang dari 12 jam.

Dalam budidaya tanaman stevia perlu penanganan yang tepat agar pertumbuhan dan produksinya maksimal dengan cara pemupukan, Pemupukan bertujuan untuk mengganti unsur hara yang hilang dengan mengunakan pupuk kimia atau mengunakan pupuk organik tetapi menurut kristanto daniel, et, al (2019) dan Roidah (2013) penggunaan pupuk kimia dalam jangka panjang dapat mempengaruhi kesuburan tanah, dan mengakibatkan pencemaran lingkungan dan mengikisnya unsur hara dalam tanah. Penggunaan pupuk organik bisa menyediakan unsur hara secara langsung bagi tanaman dan dapat memperbaiki struktur tanah, meningkatkan stabilitas agregat tanah yang dapat memelihara aerasi tanah dengan baik serta dapat menunjang peningkatan efisiensi penggunaan pupuk (Hayati et al., 2012). Salah satu jenis pupuk organik adalah pupuk kandang dan pupuk Petroganik.

Pupuk kandang ialah pupuk yang bersal dari kotoran hewan yang sudah dikomposkan/diuraikan yang memiliki kandungan hara seperti N, K, P, dan unsur lainnya. Menurut Risnandar (2004), komponen yang terpenting dari pupuk kandang adalah faces dan urine (kencing). Komponen pupuk kandang sangat bervariasi dan tergantung dari macam binatang dan makanan yang diberikan.

\section{BAHAN DAN METODE}

Penelitian ini telah dilaksanakan pada tanggal 5 September 2019 sampai dengan 22 November 2019, tempat penelitian di Dusun Tlogo Dringo, Desa Gondosuli, Kecamatan Tawangmangu, 
Kabupaten Karanganyar dengan ketinggian tempat $1800 \mathrm{~m}$ dari permukaan laut. Alat yang digunakan antara lain : Cangkul, gunting potong, ember, sabit, timbangan, tali raffia, pengaris, rol meter, sepringkel, gemboran. Bahan yang digunakan antara lain: bibit tanaman Stevia, pupuk kotoran (sapi, kambing, ayam), pupuk petroganik dan juga pupuk susulan NPK

Penelitian ini menggunakan Rancangan Acak Kelompok Lengkap (RAKL) secara faktorial dengan mengunakan 5 kombinasi perlakuan dan diulang sebanyak 3 kali, perlakuan meliputi $\mathrm{P}_{0} \mathrm{~V}_{1}=$ tanpa pupuk pada varietas Jumbo Hijau; $\mathrm{P}_{1} \mathrm{~V}_{1}=$ pupuk kotoran sapi pada varietas Jumbo Hijau; P ${ }_{2} \mathrm{~V}_{1}=$ pupuk kotoran kambing pada varietas Jumbo Hijau; $\mathrm{P}_{3} \mathrm{~V}_{1}=$ pupuk kotoran ayam pada varietas Jumbo Hijau; $\mathrm{P}_{4} \mathrm{~V}_{1}=$ pupuk Petroganik pada varietas Jumbo Hijau; $\mathrm{P}_{0} \mathrm{~V}_{2}=$ tanpa pupuk pada varietas Super Kuning; $\mathrm{P}{ }_{1} \mathrm{~V}_{2}=$ pupuk kotoran sapi pada varietas Super Kuning; $\mathrm{P}_{2} \mathrm{~V}_{2}=$ pupuk kotoran kambing pada varietas Super Kuning; $\mathrm{P}_{3} \mathrm{~V}_{2}=$ pupuk kotoran ayam pada varietas Super Kuning; $\mathrm{P}_{4} \mathrm{~V}_{2}=$ pupuk Petroganik pada varietas Super Kuning

Pengamatan tinggi tanaman dan jumlah daun, dengan membuat data secara bertahap dengan interval waktu 2 mingu setelah tanam. Pada parameter pengamatan pasca panen penulis mengamati bobot brangkasan segar, bobot brangkasan kering. Data hasil penelitian dianalisis menggunakan analisis ragam dan dilanjutkan dengan uji BNJ pada taraf 5\% untuk mengetahui adanya pengaruh di setiap perlakuan.

\section{HASIL DAN PEMBAHASAN}

\section{Pertumbuhan vegetatif tanaman Stevia (Stevia rebodiana Bertonii M)}

Sidik ragam tinggi tanaman dengan interval waktu 2 minggu setelah tanam. Hasil pengamatan menunjukan bahwa perlakuan macam varietas dan dosis pupuk organik $(\mathrm{P})$ berpengaruh sangat nyata terhadap tinggi tanaman Perlakuan pupuk kotoran ayam berbeda nyata jika dibandingkan dengan perlakuan pupuk kotoran Sapi (P1), dan Kambing (P2), tetapi berbeda tidak nyata jika dibandingkan dengan perlakuan Tanpa Pupuk (P0) dan Petroganik (P4)

Tabel 1. Tinggi tanaman stevia pada setiap perlakuan pada saat umur pengamatan

\begin{tabular}{ccccc}
\hline & \multicolumn{4}{c}{ Tinggi tanaman $(\mathrm{cm})$ setiap umur } \\
\cline { 2 - 5 } Perlakuan & $15 \mathrm{HSt}$ & $30 \mathrm{Hst}$ & $45 \mathrm{Hst}$ & $60 \mathrm{Hst}$ \\
\hline P0V1 & 6 & 9,17 & $13,5 \mathrm{a}$ & $19,5 \mathrm{a}$ \\
P1V1 & 7,08 & 10,75 & $17 \mathrm{~b}$ & $22,83 \mathrm{~b}$ \\
P2V1 & 6,75 & 10,08 & $18,42 \mathrm{~b}$ & $23,17 \mathrm{~b}$ \\
P3V1 & 7,83 & 13,08 & $22,33 \mathrm{~b}$ & $28,58 \mathrm{~b}$ \\
P4V1 & 5,92 & 9,92 & $16,08 \mathrm{ab}$ & $20,83 \mathrm{ab}$ \\
P0V2 & 5,83 & 9,33 & $14,25 \mathrm{a}$ & $19,75 \mathrm{a}$ \\
P1V2 & 7,08 & 10,75 & $19,08 \mathrm{~b}$ & $24,92 \mathrm{~b}$ \\
P2V2 & 7,25 & 11,33 & $20,5 \mathrm{~b}$ & $26,5 \mathrm{~b}$ \\
P3V2 & 8,58 & 14,42 & $23,58 \mathrm{~b}$ & $29,83 \mathrm{~b}$ \\
P4V2 & 6,58 & 10,33 & $15,67 \mathrm{ab}$ & $21,17 \mathrm{ab}$ \\
\hline
\end{tabular}

Keterangan : Perlakuan yang diikuti dengan huruf sama pada kolom menunjukan berbeda tidak nyata pada taraf $5 \%$ uji BNJ 
Dari tabel di atas menunjukan bahwa rata-rata tinggi tanaman yang paling tinggi pada perlakuan pupuk P3 yaitu dengan mengunakan pupuk kotoran ayam. Hal ini disebabkan karena pupuk kotoran ayam mempunyai kandungan bahan organik yang tinggi. Menurut pendapat Sedjati (2005) bahwa unsur $\mathrm{K}$ sangat penting dalam proses pertumbuhan bersamaan dengan unsur $\mathrm{P}$ yang mampu mengatur berbagai mekanism dalam proses metabolik seperti fotosintesis, respirasi, pembentukan bunga, perkembangan akar dan transportasi hara dari akar ke daun.

Hal ini selaras dengan peneliti Dewi, (2007) yang menyatakan bahwa pemberian pupuk organik memberikan pengaruh nyata terhadap tinggi tanaman, jumlah daun, bobot brangkasan segar, dan bobot brangkasan kering, Perlakuan pupuk kotoran ayam memberikan pertumbuhan yang lebih baik dari pada pupuk kandang yang lain menurut Susanto et al, (1999). Perlakuan tertinggi terdapat pada dua perlakuan yaitu, perlakuan pupuk kotoran ayam pada Jumbo Hijau (P3V1) dan perlakuan pupuk kotoran ayam pada Super Kuning (P3V2)

Sidik ragam jumlah daun dengan interval waktu pengamatan 2 minggu setelah tanam menunjukan bahwa perlakuan macam varietas dan dosis pupuk organik $(\mathrm{P})$ berpengaruh sangat nyata terhadap jumlah daun: Perlakuan pupuk kotoran ayam berbeda nyata jika dibandingkan dengan perlakuan pupuk kotoran Sapi (P1), Kambing (P2), dan Petroganik (P4) ,tetapi berbeda tidak nyata jika dibandingkan dengan perlakuan tanpa pupuk (P0)

Tabel 2. Jumlah daun tanaman Stevia pada setiap perlakuan pada saat umur pengamatan

\begin{tabular}{ccccc}
\hline & \multicolumn{4}{c}{ Jumlah daun (helai) setiap umur pengamatan } \\
\cline { 2 - 5 } Perlakuan & $15 \mathrm{HSt}$ & $30 \mathrm{Hst}$ & $45 \mathrm{Hst}$ & $60 \mathrm{HSt}$ \\
P0V1 & 20,33 & 37,5 & $65,67 \mathrm{a}$ & $85,83 \mathrm{a}$ \\
P1V1 & 23,58 & 57,33 & $76,33 \mathrm{~b}$ & $96,67 \mathrm{~b}$ \\
P2V1 & 23,25 & 53,17 & $75,83 \mathrm{~b}$ & $97,5 \mathrm{~b}$ \\
P3V1 & 30 & 72,5 & $95 \mathrm{~b}$ & $114 \mathrm{~b}$ \\
P4V1 & 22,17 & 45,67 & $67,5 \mathrm{ab}$ & $87,83 \mathrm{ab}$ \\
P0V2 & 20,67 & 41,67 & $64,83 \mathrm{a}$ & $84,33 \mathrm{a}$ \\
P1V2 & 23,58 & 63,67 & $80,67 \mathrm{~b}$ & $102,17 \mathrm{~b}$ \\
P2V2 & 22,67 & 60,33 & $84,17 \mathrm{~b}$ & $105 \mathrm{~b}$ \\
P3V2 & 28,5 & 72,67 & $96,67 \mathrm{~b}$ & $116,67 \mathrm{~b}$ \\
P4V2 & 21,08 & 44,25 & $65,83 \mathrm{~b}$ & $90 \mathrm{~b}$ \\
\hline
\end{tabular}

Keterangan : Perlakuan yang diikuti dengan huruf sama pada kolom menunjukan berbeda tidak nyata pada taraf $5 \%$ uji BNJ

Dari tabel di atas menjelaskan bahwa rata-rata jumlah daun yang paling banyak pada perlakuan pupuk P3 yaitu dengan mengunakan pupuk kotoran ayam. Hal ini disebabkan karena pupuk kotoran ayam mempunyai kandungan hara lebih banyak, kandungan dalam pupuk tersebut cepat terdekomposisikan sehingga pupuk ayam mudah terserap dan tersedia bagi tanaman dan tanah. Agustina (2011) Menyatakan bahwa dekomposisi/penguraian bahan organik di dalam tanah 
dibutuhkan oleh tanaman yang dapat dirubah menjadi mineral tanah oleh unsur Nitrogen dan Fosfor sedangkan cadangan nutrisi di dalam tanah dirubah oleh unsur $\mathrm{K}, \mathrm{Ca}, \mathrm{Mg}$. Terserapnya unsur $\mathrm{N}$ berpengaruh pada peningkatan jumlah klorofil daun (suputro,1996) menurut Jumin (1995), klorofil daun berfungsi sebagai proses fotosintesis, sehingga jumlah daun yang dihasilkan oleh tanaman Stevia tertinggi. Perlakuan tertinggi terdapat pada dua perlakuan yaitu, Perlakuan pupuk kotoran ayam P3 pada varietas Jumbo Hijau V1 dan yang kedua yaitu perlakuan pupuk kotoran ayam P3 pada Super Kuning V2.

\section{Pengaruh setiap perlakuan terhadap hasil panen tanaman Stevia}

Sidik ragam menunjukan bahwa perlakuan macam varietas dan dosis pupuk organik $(\mathrm{P})$ berpengaruh sangat nyata terhadap bobot brangkasan segar. Perlakuan pupuk kotoran ayam berbeda nyata jika dibandingkan dengan perlakuan pupuk kotoran Sapi (P1), Kambing (P2), dan Petroganik (P4), tetapi berbeda tidak nyata jika dibandingkan dengan perlakuan Tanpa Pupuk (P0)

Tabel 3. Rata-Rata bobot brangkasan segar

\begin{tabular}{ccc}
\hline & \multicolumn{2}{c}{ Macam Varietas (V) } \\
\cline { 2 - 3 } Pupuk Oraganik (P) & $\begin{array}{c}\text { V1 } \\
\text { (Jumbo Hijau) }\end{array}$ & $\begin{array}{c}\text { V2 } \\
\text { (Super Kuning) }\end{array}$ \\
\hline P0 & $55,42 \mathrm{a}$ & $54,58 \mathrm{a}$ \\
(Tanpa Pupuk) & $101,67 \mathrm{~b}$ & $87,50 \mathrm{~b}$ \\
P1 & $105,00 \mathrm{~b}$ & $110,00 \mathrm{~b}$ \\
(Sapi) & $133,75 \mathrm{~b}$ & $131,67 \mathrm{~b}$ \\
P2 & & \\
Kambing) & $70,83 \mathrm{~b}$ & $79,17 \mathrm{~b}$ \\
(Ayam) & &
\end{tabular}

Keterangan : Perlakuan yang diikuti dengan huruf sama pada kolom menunjukan berbeda tidak nyata pada taraf $5 \%$ uji BNJ

Dari tabel di atas menjelaskan bahwa rata rata bobot brangkasan segar yang paling baik pada perlakuan pupuk P3 yaitu dengan mengunakan pupuk kotoran ayam. Hal ini di sebabkan karena pupuk kotoran ayam mempunyai kandungan unusur NPK yang tinggi (Anonim 1993). Meningkatnya ketersedian unsur hara dalam tanah dapat berpengaruh pada serapan hara oleh tanaman, Meningkatnya serapan hara $\mathrm{N}$, $\mathrm{P}$, dan $\mathrm{K}$ dapat meningkatkan pertumbuhan vegetatif tanaman sehingga brangkasan segar yang dihasilkan tinggi. Perlakuan tertinggi terdapat pada dua perlakuan yaitu perlakuan pupuk kotoran ayam P3 pada varietas Jumbo Hijau V1 dan yang kedua yaitu perlakuan pupuk kotoran ayam P3 pada Super Kuning V2

Sidik ragam menunjukan bahwa perlakuan macam varietas dan dosis pupuk organik (P) berpengaruh sangat nyata terhadap bobot brangkasan kering: Perlakuan pupuk kotoran ayam, berbeda nyata jika dibandingkan dengan perlakuan pupuk kotoran Sapi (P1) dan Kambing (P2), tetapi berbeda tidak nyata jika dibandingkan dengan perlakuan Tanpa Pupuk (P0) dan Petroganik (P4) 
Tabel 4. Rata-Rata bobot brangkasan kering

\begin{tabular}{ccc}
\hline \multirow{2}{*}{ Pupuk Oraganik (P) } & \multicolumn{2}{c}{ Macam Varietas (V) } \\
\cline { 2 - 3 } P0 & $\begin{array}{c}\text { V1 } \\
\text { (Jumbo Hijau) }\end{array}$ & $\begin{array}{c}\text { V2 } \\
\text { (Super Kuning) }\end{array}$ \\
\hline Tanpa Pupuk) & $13,33 \mathrm{a}$ & $13,33 \mathrm{a}$ \\
P1 & $22,25 \mathrm{~b}$ & $19,00 \mathrm{~b}$ \\
(Sapi) & $20,17 \mathrm{~b}$ & $20,00 \mathrm{~b}$ \\
P2 & $24,58 \mathrm{~b}$ & $24,58 \mathrm{~b}$ \\
(Kambing) & & $15,92 \mathrm{ab}$ \\
P3 & $15,08 \mathrm{ab}$ & \\
Pyam) & & pad
\end{tabular}

Keterangan : Perlakuan yang di ikuti dengan huruf sama pada kolom menunjukan berbeda tidak nyata pada taraf $5 \%$ uji BNJ

Dari tabel diatas menjelaskan bahwa rata rata bobot brangkasan kering yang paling baik pada perlakuan pupuk P3 yaitu dengan mengunakan pupuk kotoran ayam. Hal ini disebabkan karena pupuk kotoran ayam mempunyai kandungan hara NPK yang tinggi dapat berpengaruh pada meningkatnya berat kering, karena berat kering mencerminkan tingkat nutrisi tanaman. Dikatakan Sutedjo (2010) tanaman yang kekurangan unsur hara $\mathrm{N}$ dapat menurunkan proses fotosintesis, Menurut Nurhayati, et al 2018 fotosintesis merupakan satu-satunya sumber energi bagi kehidupan tanaman selama pertumbuhan sebab unsur hara N diperlukan tanaman untuk membentuk krolofil daun (Seputro, 1996). Terhambatnya proses fotosintesis dapat menurunkan pembentukan berat kering. Perlakuan tertinggi terdapat pada dua perlakuan yaitu perlakuan pupuk kotoran ayam P3 pada varietas Jumbo Hijau V1 dan yang kedua yaitu perlakuan pupuk kotoran ayam P3 pada Varietas Super Kuning V2.

\section{KESIMPULAN}

Perlakuan pupuk organik berpegaruh nyata terhadap pertumbuhan dan hasil tanaman Stevia baik pada vaeietas Jumbo Hijau (V1) maupun pada varietas Super Kuning (V2), sedangkan perlakuan tanpa pupuk tidak berpengaruh nyata pada varieats Jumbo Hijau (V1) maupun Super Kuning (V2) Perlakuan pupuk Petroganik tidak berpengaruh nyata terhadap pertumbuhan dan hasil tanaman stevia jika dibandingkan dengan perlakuan tanpa pupuk. Pengunaan pupuk kotoran ayam dengan dosis 2 $\mathrm{kg} /$ per petak menunjukan pertumbuhan vegetatif tanaman stevia lebih tinggi dari semua perlakuan yang di uji, baik pada varietas Jumbo Hijau (V1) Dan Varietas Super Kuning (V2) 


\section{DAFTAR PUSTAKA}

Agustina, L. 2011. Teknologi Hijau dalam Pertanian Organik Menuju Pertanian Berlanjut., Malang, UB Press

Anonim, 1993, Efektif Microorganisme, Jakarta, Senggon Langit Persada

Daniel Kristanto, Priyono, Saiful Bahri (2019), "Uji Pupuk Hayati Terhadap Pertumbuhan Dan Hasil Ubi Jalar (Ipomea batatas L). ISSN (Print): 1693-0738 Innofarm:Jurnal Inovasi Pertanian Vol. 21 (2), Oktober 2019

Dewi, L. R. 2007. Pemberian Kompos dan Unsur Kelumit terhadap Pertumbuhan dan Kandungan Gula Stevia Tanaman Stevia (Stevia Rebaudiana Bertoni M.),. Institut Pertanian Bogor, Fakultas MIPA, Indonesia.

Hayati, E., Sabarudin, dan Rahmawati. 2012. Pengaruh jumlah mata tunas dan komposisi media tanam terhadap pertumbuhan setek tanaman jarak pagar (Jatropha curcas L.).. Agrivista. 3:129-134

Jumin, H B., 1995. Dasar - Dasar Agronomi., Jakarta. Rajawali Press. $193 \mathrm{Hal}$

Kementan. 2012. Pedoman Teknik Studi Kelayakan Pabrik Gula mini. Derektorat Pengembangan Usaha dan Investasi ,Derektorat Jenderal Pengolahan dan Pemasaran Hasil Pertanian

Nurhayati D, R,Yuduno P, Taryono, dan E . Hanudin (2018) , Pengaruh waktu pemupukan pada dua musim tanam terhadap karakter wijen Sbr-1dan Sbr-3 di Lahan Pasir Pantai. Journal of sustainable agriculture 33(1), 19-25 hal.Caraka Tani

Risnandar C 2004 .Jenis dan Karakteristik Pupuk Kandang. http://www.alamtani.com/pupukkandang.htm \{diakses pada desember 2016\}

Roidah, I. S. (2013). Manfaat Penggunaan Pupuk Organik Untuk Kesuburan Tanah. Jurnal Universitas Tulungagung.

Seema, T. (2010). Stevia rebaudiana: A medicinal and nutraceutical plant and sweet gold for diabetic patients. International Journal of Pharmacy and Life Sciences, 1(8), 451-457

Susanto, S Dan M. Syukur. 1999. Pengaruh Lumpur Buangan Dan Pengelolaan Limbah Sintesis Antibiotika Dan Pupuk Kandang Terhadap Pertumbuhan Dan Produksi Stevia (Stevia Rebaudiana Bertoni M.). Bul. Agron.27(2): 1-7 (Abstr).

Suputro, D., 1996, Pengantar Fisiologi Tumbuhan, Jakarta. Gramedia, 231 Hal

Sutedjo, M.M 2010. Pupuk dan Cara Pemupukan. Jakarta: Rineka Cipta

Syukur, M. 1996. Pengaruh Pemberian Lumpur Buangan Dari Pengolahan Limbah Sintesis Antibiotika dan Pupuk Kandang Terhadap Pertumbuhan dan Produksi Stevia rebaudiana Bertoni M. Skripsi. IPB 